\title{
Guidelines for the Development of Restaurant Businesses: Providing Online Food Delivery Services in Khon Kaen, Thailand
}

\author{
Jenasama Srihirun $^{1}$, Butsayamat Chaiwinitm ${ }^{2}$, Nawarat Chatphum ${ }^{3}$, Yuttapong Tonpradoo ${ }^{4}$ \\ ${ }^{1,2,3}$ Faculty of Business Administration and Accountancy, Khon Kaen University, \\ ${ }^{4}$ Faculty of Fine and Applied Arts and Cultural Sciences, Mahasarakham University \\ ${ }^{1}$ jenasama.srihirun@gmail.com, jenass@kku.ac.th, ${ }^{2}$ butsayamat.c@kkumail.com, ${ }^{3}$ nawarat_c@kkumail.com, \\ 4yuttapong.t@msu.ac.th
}

\begin{abstract}
This research aims to find the guidelines for developing the restaurant businesses providing online food delivery services in Muang District, Khon Kaen Province, Thailand. Qualitative research was utilized to conduct the research. There were two techniques: namely, Documentary research and In-depth interviews (IDI) with seventeen key informants with at least five years of business experience. The study found that $9 \mathrm{M}$ (Man, Money, Materials, Management, Morale, Message, Marketing, Menu, and Mindset) led to the business-critical successes. Place or distribution channel was an important factor for service marketing mixed factors. The finding showed three service innovations: 1) New service concepts, 2) New service processes, and 3) New service business models for the guidelines to develop restaurant businesses providing online food delivery services.
\end{abstract}

Keywords

Guidelines for Development, Restaurant Businesses, Online Platform Food Delivery Services

Article Received: 10 August 2020, Revised: 25 October 2020, Accepted: 18 November 2020

\section{Introduction}

The restaurant business statistics in the United States indicated the failure rate of more than $60 \%$ of all restaurants. Many entrepreneurs have had problems since the first year of operation, and nearly $80 \%$ will shut down after five years of operation. From 2016 to 2017, the number of independently owned restaurants in New York declined by $2 \%$. Also, from 2005 to 2015 , there were many reasons for restaurant businesses failures. One of the most common causes was the restaurant's location, consumer behaviors, and restaurant management. The same was true for restaurant businesses in Thailand, where there was a lower 5-year retention record [1] [2], while the past five years (the year's 2014-2018) Thai SMEs Center provided information that the restaurant businesses using an online food delivery platform in Thailand have continued to grow by $14 \%$, growing more than the non-delivery restaurant businesses with an average growth of only $3-4 \%$ per year.

Moreover, the Kasikorn Research Center analysis had assessed the restaurant business situation in Thailand in 2020 , concluding that revenues of approximately 400 billion baht or a decrease of $2.65-3.65$ billion baht compared to the revenue of 2019. Restaurant businesses in Khon Kaen province, adjusted to do business by maintaining service standards following clean, safe and hygienic principles following the announcement of urgent measures to prevent the spread of the epidemic and infectious disease COVID 19 for restaurant businesses, including finding out how to provide food via online food delivery channels [3] [4]

With technology, demographic structure and consumer behavior changing. Including the restaurant management innovation that must create competitiveness for the businesses' survival; this makes the researcher need to find the guidelines to develop the restaurant business through online food ordering platforms that are in line with today's consumer behavior. It will also need to search a new service model and restaurant management innovation. This research case study focused on Khon Kaen, Thailand.

\section{Research Objectives}

This research aims to find a guideline to develop the restaurant business providing online food delivery services in Khon Kaen province, Thailand.

\section{Research Methods}

\section{A. Research Design}

This research was qualitative research. Documented research had established criteria for document selection according to Scott's guidelines (1990); (2006) as follows: 1) Authenticity, 2) Credibility, 3) Representativeness, and 4) Meaning. [5] The scope of the content focuses on the theoretical concepts related to Business Factors (4Ms) [6], Service Marketing Mixed (7Ps) [7], and Service Innovation [8].

Semi-structured Interview form with the open-ended question was a research tool for In-depth interviews (IDI) with seventeen key informants who have at least five years of experience in the business, divided into two groups as follows: 1) Thirteen Restaurant business owners who provide online food delivery service and 2) Four of the platform service providers in online food delivery. The data collection method was done until the data reached the Theoretical Saturation, so the researcher stopped collecting data. The method for determining the reliability of the data was Triangulation. There are two aspects of triangulation: 1) 
Data Triangulation by examining the source of time, place, person, and 2) Theory triangulation. [9] The data analysis began with the extraction of sound recordings from mobile phones in writing. Holistic analysis and Content analysis like the correlation of the study results lead to the conclusion of the key variable issues. [10]

\section{B. Research Process}

The research process of this research has developed into six steps consisted of 1) analyzing concepts 2) creating the research tool 3) examining the research tool 4) data collection 5) finding the results and 6) the research discussion, conclusion and recommendation.

\section{Research Conceptual Framework}

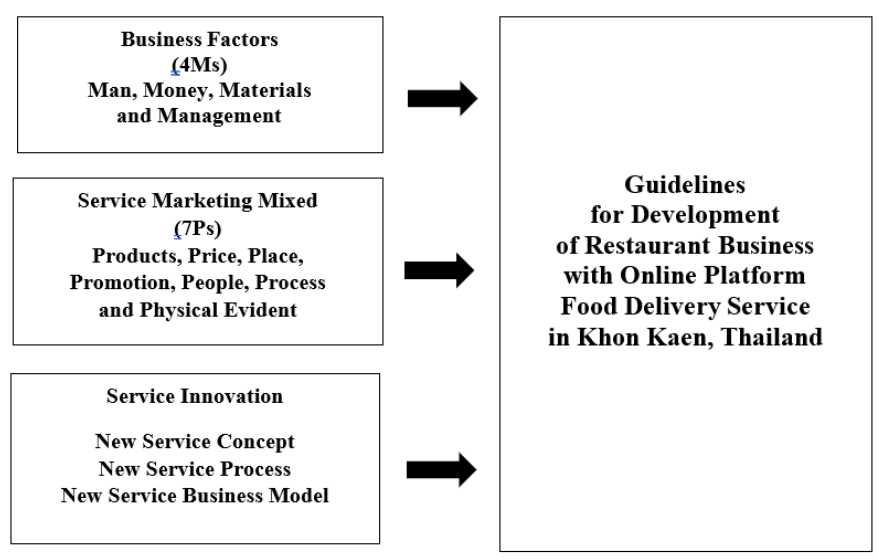

Fig.1 Research Conceptual Framework

\section{Results}

Business Factors for running restaurants providing online food delivery in Khon Kaen, Thailand

From the research, it was found that Business Factors for running a restaurant providing online food delivery in Khon Kaen, Thailand was 4-M as follows:

1st M - Man: the business was considered in term of the quality and development of employees' potential regularly in the organization. This included the management of training to increase knowledge and work skills 2nd M - Money: the businesses had the investment allocation for restaurants $3 \mathrm{rd}$ M - Material: Be updated with the most current food items in the online ordering service. To facilitate the customers at any time and 4th M - Management: planning to control the business's operating expenses and search for distribution channels of food and beverages to increase income for the organization. The organization focuses on dividing work according to position, function according to the structure and organization chart with the emphasis on work orders, monitoring, supervising, and coordinating customer service. However, research has found the restaurants' success factor providing online food delivery from $4 \mathrm{M}$ to $9 \mathrm{M}$, with the 5th $\mathrm{M}$ being $\mathrm{M}$ - Morale: this gives importance to personnel involved in business operations. The 6th $M$ was $M$ Message was to provide information to customers, build networks and communication systems for customers. The 7th $\mathrm{M}$ was the $\mathrm{M}$ - Menu, which is a unique menu or signature menu. The 8th $\mathrm{M}$ is $\mathrm{M}$ - Marketing was the process of communicating the value of a product or service to the customer, and the 9th M was M - Mindset. That needs to be flexible and up-to-date for business efficiency as shown in Fig. 2

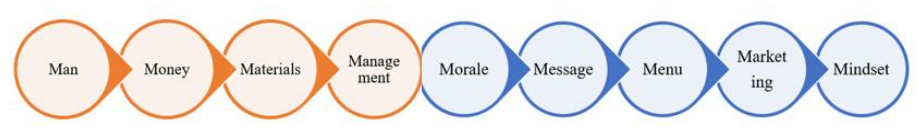

Fig.2 Develop fundamental business factors from $4 \mathrm{M}$ to $9 \mathrm{M}$

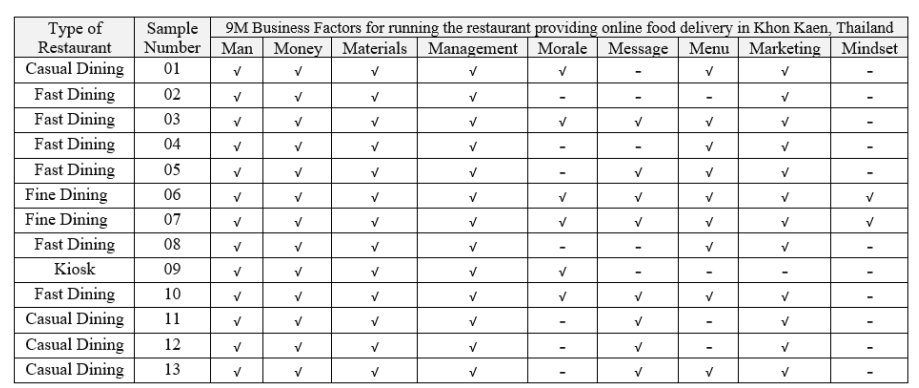

Fig.3 9M business factors for running restaurants providing online food delivery services in Khon Kaen, Thailand

From Fig.3, it can be explained that there were thirteen leading and legendary restaurants providing online food delivery in Khon Kaen, Thailand. [11] It was divided into four types of restaurants. namely, 1) Fine dining 2) Casual dining 3) Fast dining and 4) Kiosk. [12] The figure 2 shown that All types of restaurants of the 13 samples accounted for $100 \%$ of the total restaurant samples. There were $4 \mathrm{M}$ fundamentals in business factors: Man, Money, Materials, and Management. In all restaurants, 6 samples accounted for $46 \%$ of the total restaurant samples. There was a factor in operating the business of M - Morale. Especially, Kiosks and Fine dining restaurants place a high priority on employee morale. As for M-Message, which was to provide information and build good relationships with customers, it was available in the categories of Fast dining, Fine dining and Casual dining, account for 54\% of the total samples. Fast dining, Casual dining, and Fine dining restaurants operate the M-Menu, accounting for $69 \%$ of the total samples. The menu has been adjusted to be in line with the online food ordering service, especially Fast dining. Kiosk restaurants focused on the $4 \mathrm{M}$ fundamentals over $\mathrm{M}$ Marketing, while other restaurants focused on. For Fine dining restaurants the main factor in the online food delivery business were M - Mindset, and 9 M were Man, Money, Materials, Management, Morale, Message, Menu, Marketing, and Mindset.

\section{Service Marketing Mixed for running restaurant providing online food delivery in Khon Kaen, Thailand}

From the research results, it was found that 1) Product factors: The restaurant business places great emphasis on the food items that focus on creating unique and signature menus of the restaurant referring from interviews of owners of Casual dining, Fast dining and Fine dining restaurant. "Our restaurant was constantly developing food products. Adjusted the menus and created a new and signature food menu. Using quality, local ingredients, and food trends to always respond to customer needs.” 2) Price factor: Casual 
dining, Fast dining, and Kiosk restaurants set selling prices through online ordering, with the selling price rising at 5 10 Baht per menu, while Fine dining restaurants set prices for dine-in and selling through the online food ordering platform at the same price. There was only a charge for the food delivery. "Fine dining restaurant owner said that "Most of the food menus sold in the restaurant and those that provide food delivery services were through online applications. Both of them were sold at the same price, but the restaurant selects the menu that was easy to cook and does not take a long time and can be packaged in a container for delivery to the customers quickly, keeping the quality of the food for a good taste." Some platform service providers offer free online food delivery service. 3) Place factor: At most dining in all restaurants, there was often a place to serve food for taking away and delivery through online platforms, including outside catering services. However, some Kiosk type restaurants were more focused on selling in front of the restaurant than the online platform. Nevertheless, selling like this was quite high in distribution costs. Sometimes it was not worth the selling price and raw materials' cost, so it was canceled." While, some platform service providers have expanded their service branches to cover 77 provinces in the whole of Thailand. 4) Promotion factor: The discount coupon with a minimum order condition, buy one get one free for food order, Offer the combination set menu to create value, and attract consumers. including the free delivery charge. 5) People factor: All types of restaurant businesses were importance on service for both consumers and delivery food driver. Some of fine dining restaurant mentioned that "Our restaurants always had a standard of procedure in training employees before starting work." While the Platform service provides insurance driver during the operation. It has a high coverage limit of up to 200,000 baht, a leader of a platform service provider said. 6) Process factor: The process had convenient ordering process. There were various payment methods. Able to contact the service provider as soon as the problem arises and had an accurate delivery situation monitoring system. Also, food and beverage cost control were important for each restaurant and 7) Physical evidence factors: The food menu was clearly categorized and easy to understand. Food photos with a unique menu and showing the identity of the restaurant were provided. The pictured food items were exactly the same as the image used to advertise the menu, it had a promotion, an online food ordering app and restaurant information complete. In addition, some platform service providers provide the tablet that was a tool for online ordering between restaurants and customers to their partner outlets.

\section{Service Innovation of Restaurant Business Providing Online}

Food Delivery Service in Khon Kaen, Thailand

According to the research, it was found that Guidelines for the development of the restaurant business providing online food delivery service in Mueang District Khon Kaen Province, Thailand has the following service innovations.

1) A New Service Concept was introduced in restaurants offering online food delivery. Food and beverage services were available in Take away, Outside catering service, Monthly lunch and/or dinner delivery in tiffin styles, and Ready to cook for the home cooking set which consisted of raw materials, other ingredients, including a combination set menu called the combo set. Food and beverage according to various festival themes in order to present new food items to customers. Many Casual Dining and Fast Dining restaurant owners, allowed the same direction for the platform service provider in online food delivery in Khon Kaen within many new service concepts. 2) "We have played an important role in service improvement such as proper containers for food delivery, environmentally-friendly designed packaging materials, quality service of chef, staff and driver for customers' satisfaction." More than $70 \%$ of restaurant owners especially, Casual Dining and Fast Dining did this and agreed with the same emphasis. For platform service providers, mostly they were concerned about a good drivers' qualifications: politeness, good service and the accountancy of the routing. While, each type of restaurant has to try to produce with uniqueness, lift up the local wisdom and match nationwide and international levels. 3) Some fine dining restaurants which provide online food delivery exceed customers' expectations by offering some special food of the day or some new food items to provided complimentary. 4) Process of cooking before delivering time was managed for working efficiency. referring to "Our restaurant, normally, we set cooking time to no more than fifteen minutes per menu." Ten of Thirteen restaurants mentioned this. 5)Some of the Fast Dining restaurants, which have more than one outlet, had their own delivery system and riders for online food delivery service. However, they still used the services of leading platform online food delivery companies as well. 6) Platform service providers in online food delivery, set the new service process in their platforms, adding customer engagement channel in the application, development service delivery system especially creating marketing promotion strategies for upselling food through the platform. "Our platform provides attractive marketing promotion to boost up revenue for our restaurant partners as a local platform service provider mentioned." 7) Many restaurant businesses have changed the business model to be the "Cloud kitchen model" which was a restaurant without a storefront. Provide food service by delivering food to customers. While the store is mainly used for cooking and accepting online food orders through the application. Their goal was competitiveness in expanding branches and reduces operating costs. There were also more channels to distribute products through online trading channels using various related online applications or marketing tools. "Our restaurant business has adjusted a business model to focus on the central kitchen for cooking and delivering food in the form of delivery or picking up food at restaurants. Rather than sitting and eating at the restaurant" which is a new service business model 8) A new service monetization model that adds value to the restaurants' foods, such as the introduction of the Omakase concept, the Chef's Table in Japanese style, refers to indulging the chef', that was, eating food without us choosing the menu itself. For each menu served, the chef arranges it for us. Most of the food menus were selected from the finest ingredients and the best cooking processes 
that brings out the value the flavor and the uniqueness of the food for the customers to experience, taste and experience. For example, Fine Dining and Casual Dining restaurant businesses adopt this form in their mode of operation. And also creating new market segments that were unique and able to build a cooperative network of trade partners in delivering quality raw materials in the supply chain system as shown as Fig. 4

\begin{tabular}{|c|c|c|}
\hline $\begin{array}{l}\text { New Service } \\
\text { Concept }\end{array}$ & $\begin{array}{c}\text { New Service } \\
\text { Process }\end{array}$ & $\begin{array}{c}\text { New Service } \\
\text { Business Model }\end{array}$ \\
\hline $\begin{array}{l}\text { - Novel Offering } \\
\text { Take Away } \\
\text { Outside Catering } \\
\text { Online Food Delivery } \\
\text { Ready to Cook for Home } \\
\text { Cooking } \\
\text { - Beyond Expectation } \\
\text { Service } \\
\text { - Product Development } \\
\text { - Service Improvement }\end{array}$ & $\begin{array}{l}\text { - Delivery Service Process } \\
\text { - Cooking Time Control } \\
\text { Process } \\
\text { - Marketing Strategies }\end{array}$ & $\begin{array}{l}\text { - Cloud Kitchen } \\
\text { - Omakase / Chef 's Table } \\
\text { - New Market Segment } \\
\text { - Build Cooperative } \\
\text { Network }\end{array}$ \\
\hline
\end{tabular}

Fig.4 Service Innovation of Restaurant Business Providing Online Food Delivery Service in Khon Kaen, Thailand

\section{Discussions}

The result found that $9 \mathrm{M}$ consists of Man, Money, Materials, Management, Morale, Message, Menu, Marketing, and Mindset which was a fundamental business factor for running restaurant providing online food delivery in Khon Kaen, Thailand that related research to [13] Unileverfoodsolution institution mentioned that there were four factors namely $4 \mathrm{Ms}$ to running a successful restaurant by learning how Money, Materials, Manpower, and the Market can make restaurants successful. According to the concepts of Dokchan Kammeerat, Boonthan Dokthaisong, and Imron Malulim (2009) [14] and Harold Koontz (1980) there were four key administrative resources: 1) Human Resource Management (Man) 2) Money, 3) Material and 4) Management [15], which was as the same way direction with Wichian Witthayudom (2007) [16] Somkid Bangmo (2009) [17]. agreed with this concept. However, four additional important factors were discovered, including 8 factors, namely M-Market, M- Machine, M-Morale, and MMethod While Wirach Wirachnipawan offered factors in modern management $9 \mathrm{M}$ as follows: 1) Man 2) Money 3) Material 4) Management 5) Market 6) Morality 7) Message (Public Relation and giving the information) 8) Minute (Time Management) and 9) Measurement [18]

Based on the research results in the service marketing Price and Process were consistent with the results of Natthasat Panyana and Watcharapot Sub-Sa-nganbun (2019) that focused on organizing the process system. When the cooking process was easy and convenient, it took a short time to cook and come up with reasonable prices with food quality which was consistent with the research results on service innovation related to New Service Process in Cooking time and Delivery service as well. [19] From the research, it was found that the Place or distribution channel factor which was a very important factor in the current restaurant business. Which has both online food ordering channels Including the development of channels to reach more products and services. This was consistent with the research of Sirikanya Inkhumwong (2018) [20] and Arunrat Onyen (2017) [21], and was also in line with the concept and theory of Rattawit Thongpakdee (2018) [22], Belanche (2020) [23], Cahyani (2020) [24], which said that Place or the distribution channels of the restaurant business that provide online food delivery service should have a variety of distribution channels to create greater awareness and reach to make it easier for consumers to order food. Especially the Generation Y group who used and were very familiar with technology. The research on the restaurant business's product factors focused on the food items that emphasize the creation of unique restaurant menus. This was consistent with the research of Nisa Tamsampaolert (2017) [25], while Natthawut Rungsathienphuthon (2016) [26] and Supanan Wattanawichit (2017) [27] found that the quality and nutritional value factors of food were more important. Furthermore, from the research results on People factor, the results were consistent with Supanan Wattanawichit (2017) [27] work that emphasizes human factors related to service quality.

From the research results, it was found that the restaurant business development approach for online food delivery service in Muang Khon Kaen District, Thailand depended on the development of service innovation. There were 3 service innovations as follows: 1) New Service Concepts, 2) New Service Processes, and 3) New Service Business Models, which were presented as the new concepts of product development, product line extension, changing of service providing. service Improvement and having a concept of serving customers beyond expectations. There are were improvements in the process, service procedures, and marketing strategies in order to increase the channels for generating income and build relationships with customers, which were in line with Peder Inge Furseth's concept of the service innovation triangle (2013) [8] and Christopher Lovelock and Lauren Wright. (2002) [28] that emphasize the value of service delivery and create a good experience for customers through human resource development and to foster innovation in service delivery through technology in various platforms and also new business models [29] such as cloud kitchen [2].

\section{Recommendations}

\section{Recommendations for Practices}

1) There should be a study of integrated innovation management in addition to service innovation in order to develop the business to be modern and prepare for the changes in the world that come quickly.

2) Further studies of risk and crisis management models should be undertaken due to high uncertainty in today's businesses, both internal and external factors such as hygiene management. Safety in life and property or the global public health situation regarding epidemics and COVID 19 infections, climate change, floods or wildfires, etc.

3) A conceptual framework for sustainable management that considers society, economy and the environment. It is 
important to apply this approach to the development of the online food delivery restaurant business.

\section{Recommendations for Further Research}

1) There should be quantitative research and data collection with a sample of consumers to understand and know the insight behavior of consumer service decision in order to plan the marketing strategy.

2) In qualitative research, the number of key informants who own each type of restaurant businesses should be equal amount, including in-depth interviews with other stakeholders, such as business partners, suppliers, delivery drivers. As well as data collection by focus group discussion.

3) If the research area is expanded to a wider area, regional or national or international, the data obtained can be analyzed, compared, and can be made into a management plan for restaurants providing online food delivery platforms in each area.

\section{Conclusion}

In conclusion, the findings from the qualitative analysis showed that $9 \mathrm{M}$, which consists of Man, Money, Materials, Management, Morale, Message, Marketing, Menu, and Mindset was a key success factor for running the restaurant providing online food delivery in Khon Kaen, Thailand. Place or distribution channel was an important essence for service marketing mixed factor. The finding has shown three service innovations: 1) New service concepts of product development, product line extension, changing of service providing. service improvement and having a concept of serving customers beyond expectations. 2) New service process from Delivery service process, Cooking time control process and Marketing Strategies 3) New services business models such as Cloud Kitchen and Food delivery ordering through an online application platform for the guideline to develop the restaurant business providing online food delivery services.

\section{References}

[1] CNBC. (2016). The No. 1 thing to consider before opening a restaurant. Retrieved 2016, July 6 from www.cnbc.com

[2] Jenasama Srihirun and Orapan Pangkaew. (2020) Cloud Kitchens: Opportunities and Challenges of the Restaurant Business. Southeast Bangkok Journal. Vol. 6 No.2 July-December 2020: 99-115

[3] [3] KasikornResearch. (2020, March 10). Econ Digest: "Restaurant Business 2020, Be Quiet and Expected the revenue has shrunk by more than 30 billion baht". Retrieved from KasikornResearch: www.kasikornresearch.com/th/analysis/ksocial-media/Pages/Covid19-Food.aspx

[4] ThaiSMEsCenter. (2019 December, 12). Opportunity Food App in Thailand 2020. Retrieved from ThaiSMEsCenter: www.thaismecenter

[5] Scott, J. A Matter of Record: Documentary Sources in Social Research. Cambridge: Policy Press, 1990.

[6] Social Research and Documentary Sources. Sage Benchmarks in Social Research Methods, Documentary Research Volume 1. SAGE Publication, 2006.

[7] Siriwan Sereerat (2002) Organization and Management. Bangkok: Dharmasarn Printing House.

[8] Kotler, P. (2016). Marketing Management: Analysis, Planning, Implementation and Control (15th Global ed.).Upper Saddle River, NJ: Prentice-Hall

[9] Peder Inge Furseth. (2013) The service innovation triangle: a tool for exploring value creation through service innovation. Int. J. Technology Marketing, 8 (2), 159-176.

[10] Supang Chantavanich. (2013) Qualitative ResearchMethods. 21st edition. Bangkok: Chulalongkorn Press: 2013:129-130

[11] Bussakorn Cheawjindakarn. (2018). Qualitative Case Study Research Techniques. Liberal Arts Review. Vol.13 Issue. 25. January to June 2018: 103-118

[12] Wongnai. (2020, August 20). 20 legendary restaurants in Khon Kaen. Retrieved from www.wongnai.com/listings/must-tryrestaurants-khonkaen

[13] Department of Business Development. (2019, September 3)

[14] Type of Restaurant. Retrieved from www.dbd.go.th

[15] Unileverfoodsolution. (2020, September 25). $4 \mathrm{Ms}$ to run successful restaurant Retrieved from www.unileverfoodsolutions.com.ph/chefinspiration/chef manshipacademy/module-5-principles-of-food- 
preparation-introduction/topic-3-4-ms-torunning-a-successful-restaurant.html

[16] Dokchan Kammeerat, Boonthan Dokthaisong, and Immron Malule $M$. (2009). Management strategy of the company. NEC Tokin electronics (Thailand) Co., Ltd. Retrieved 22 August 2020 , from www.grad.vru.ac.th/download4/141.pdf

[17] Harold Koontz referred to in Sompong Kasemsin (1980). Administration. 7 editions, Bangkok: Thai Wattana Panich

[18] Wichian Witthayudom. (2007). Organization Development. Bangkok: Thanawat Printing

[19] Somkid Bangmo (2009) Organization and Management, Bangkok: Wittayapat.

[20] Wiruch Wiruchnipawan. Management Administration and Strategic Administration of the State Agencies. Bangkok, Forepace Publishing House

[21] [19] Natttasat Panyana and Watcharapoj Sapsanguanboon. (2019) Factors Affecting the Decision Making in Thai Food Cooked to Order and Delivery. Economics and Business Administration Journal Thaksin University. 11 (1), 53-66.

[22] [20] Sirikanya Inkhawong (2018). Decision of consumers who choose to use food delivery service in Pak Kret area. Nonthaburi Province in the marketing mix. Thesis Master's Degree in Management Science of North Bangkok University.

[23] Arunrat Onyen. (2017). Factors relevant to decision-making to buy food from delivery business of students from Phranakhon Rajabhat University. Thesis of Master Degree of Home Economics Technology. Rajamangala University of Technology Phra Nakhon

[24] Rattawit Thongpakdee. (2018). 30 Secret Marketing Strategies). Nonthaburi: Think Beyond Books.

[25] Belanche. (2020). Mobile apps use and WOM in the food delivery sector: The role of planned behavior, perceived security and customer lifestyle compatibility. Sustainability (Switzerland). 12 (10), Article number 4275.

[26] Cahyani. (2020). Popularity Analysis of Mobile Food Ordering Apps in Indonesia. 20202 IEEE 7th International Conference on Industrial Engineering and Application, ICIEA 2020. Article Number 9102024, 1000-1004.

[27] Nisa Tamsampaolert. (2017). Decision process for ordering lunch delivery through food delivery media. Academic Conference for National Research 2018, Bangkok University, pages 708-717.

[28] Natthawut Rungsathienphuthon (2016). Types of restaurants, food quality, service quality, and social network affecting customer's decision to choose restaurants for dinner in Bangkok. Independent Study of Master's Degree, Bangkok University.

[29] Supanan Wattanawichit. (2017). Satisfaction in using Grab Food application for food delivery service of private company employees in Bangkok. Ramkhamhaeng University.

[30] Patcharee Thongrueng. (2013) Concepts and theories of innovation management for development. Bangkok

[31] Christopher Lovelock and Lauren Wright. (2002) Principles of Service Marketing and Management. 2nd Edition. Prentice Hall, USA 